\title{
Development of fear and guilt in young children: Stability over time and relations with psychopathology
}

\author{
ERIKA BAKER, ${ }^{a}$ EUGENIA BAIBAZAROVA,,${ }^{a}$ GEORGIA KTISTAKI, ${ }^{a}$ KATHERINE H. SHELTON, ${ }^{a}$ \\ AND STEPHANIE H. M. VAN GOOZEN ${ }^{a, b}$ \\ ${ }^{a}$ Cardiff University; and ${ }^{b}$ Leiden University
}

\begin{abstract}
Extremes in fearful temperament have long been associated with later psychopathology and risk pathways. Whereas fearful children are inhibited and anxious and avoid novel events, fearless individuals are disinhibited and more likely to engage in aggressive behavior. However, very few studies have examined fear in infants from a multimethod and prospective longitudinal perspective. This study had the following objectives: to examine behavioral, maternal reported, and physiological indices of fearful temperament in infancy, together with their relations and stability over time; and to establish whether early indices of fear predict fear later in toddlerhood. We also examined the association between behavioral and physiological measures of fear and guilt and whether fear in infancy predicts guilt in toddlers. Finally, we investigated infant risk factors for later psychopathology. We recorded skin conductance level (SCL) and heart rate (HR) and observed children's responses during a Laboratory Temperament Assessment Battery fear paradigm across the first 3 years of life and during a guilt induction procedure at age $3(N=70)$. The results indicate that different measures of infant fear were associated across time. Observed fearlessness in infancy predicted observed fearlessness and low levels of SCL arousal to fear and guilt in toddlers. Low levels of HR and SCL to fear in infancy predicted low levels of physiological arousal to the same situation and to guilt 2 years later. Fear and guilt were significantly associated across measures. Finally, toddlers with clinically significant internalizing problems at age 3 were already notably more fearful in Year 1 as reflected by their significantly higher HR levels. The results indicated that assessments of children in infancy are predictive of how these children react 2 years later and therefore lend support to the idea that the emotional thermostat is set in the first 3 years of life. They also showed, for the first time, that infant fear is a predictor of guilt, which is an emotion that develops later. The implications of these findings for our understanding of developmental psychopathology are discussed.
\end{abstract}

Individual differences in fearfulness have been the focus of considerable developmental research in the last few decades. Fearful individuals are characterized by behavioral inhibition; they tend to avoid risky acts and punishment and become physiologically aroused with unfamiliar people, situations, and events (Hirshfield, Biederman, Brody, Faraone, \& Rosenbaum, 1997; Hirshfield-Becker et al., 2003). Fearfulness in early childhood has been found to predict behavioral inhibition in later childhood, which is in turn associated with anxiety and depression in later life (Biederman et al., 1993; Schwartz, Snidman, \& Kagan, 1999).

Conversely, children who are temperamentally fearless are behaviorally disinhibited; they display high approach and lack of restraint to novel and unfamiliar people and situations (Hirshfield-Becker et al., 2003). Fearlessness is associated with higher levels of externalizing symptoms (Colder, Mott, \& Berman, 2002), and fearless individuals are more likely to engage in aggressive and antisocial behavior because

We are very grateful to the mothers and children who participated in the study. We also thank Justin Savage for his technical support throughout the study. The research was made possible through $\mathrm{PhD}$ studentships from Cardiff University's School of Psychology.

Address correspondence and reprint requests to: Stephanie van Goozen, School of Psychology, Cardiff University, Tower Building, Park Place, Cardiff CF10 3AT, UK; E-mail: vangoozens@cardiff.ac.uk. they do not fear the negative consequences of their behavior (Raine, 1993).

Extremes in fearful temperament have long been associated with later psychopathology and risk pathways. However, there are three limitations in this line of work. First, there is a lack of prospective, longitudinal research from infancy onward examining the stability of fearful temperament. Second, few studies have used a multimethod approach in which physiological parameters are assessed, as well as behavioral and maternally reported emotion. Third, we know very little about the associations between fear and later emerging emotions, for example, moral emotions such as guilt, which also play an important role in the development of internalizing and externalizing psychopathology (Stuewig, Tangney, Heigel, Harty, \& McCloskey, 2010). As a result, our understanding of the early development of fearful temperament is limited. We address these limitations in this study by measuring fearful temperament longitudinally from infancy through to early childhood. In addition, we investigate the association between early fearfulness and the development of guilt later in childhood.

\section{The Development of Fear}

Past research in child psychopathology has focused almost exclusively on school-aged children (Calkins \& Dedmon, 
2000). It is important to improve our understanding of the development of children's temperament across early childhood, because we know that temperament is an underlying factor that can facilitate or inhibit children's socioemotional functioning (Blandon, Calkins, Keane, \& O'Brien, 2010). Individual differences in fearful and fearless temperament are posited by some to be relatively stable over time (Buss \& Plomin, 1984), whereas others argue that temperamental changes occur as a result of neurobiological changes (Blandon et al., 2010; Derryberry \& Rothbart, 2001). Further research is needed to understand the stability of fear in order to make predictions about how it develops over time.

Although fear has been studied in infants (Kagan, 1982; Kochanska, Coy, Tjebkes, \& Husarek, 1998; Schwartz et al., 1999), much less research has focused on the development of fear from infancy onward. Studies that have investigated the stability of fear from infancy failed to find consistency with respect to the age at which fear becomes a stable temperament characteristic. Kochanska (2001) investigated fear from 9 months, finding stability from 14 months onward; whereas Lemery and colleagues began their investigation at 3 months, finding some stability from 24 months, but only intermediate forms of fearfulness were stable (Lemery, Goldsmith, Klinnert, \& Mrazek, 1999). These studies used only one method of assessment (observational or mother reported fear, respectively).

Finding stability in fearfulness and fearlessness has significant implications for later psychopathology. Fearfulness in early childhood has been associated with shyness and internalizing psychopathology, including agoraphobia, panic disorders, and multiple anxiety disorders (Biederman et al., 1993; Biederman, Rosenbaum, Hirshfield, \& Faraone, 1990; Schwartz et al., 1999). Many externalizing behavioral problems also have an early onset. The Diagnostic and Statistical Manual of Mental Disorders requires many behaviors to be apparent before middle childhood. However, the vast majority of developmental research into risk pathways for externalizing disorders studies children from middle childhood onward. Mothers of children with externalizing behavioral problems have reported that their children were difficult and irritable as infants (Weiss \& Hechtman, 1993). Frick (2004) has suggested that certain temperamental characteristics observed in infants could actually be symptoms of externalizing behaviors. Regardless of temperamental risk factors for aggression that are seen in infancy, such as a difficult temperament, there is a lack of longitudinal data to identify risk pathways.

Kagan and colleagues examined early temperament, identifying profile patterns in children at 21 months of age. Children were classified as either inhibited or uninhibited. Inhibited children were identified as being fearful, avoiding novelty, and displaying a higher heart rate (HR) during unfamiliar situations (Kagan, Reznick, Clarke, Snidman, \& Garcia-Coll, 1984; Kagan, Reznick, \& Snidman, 1987). Uninhibited children were identified as being fearless, approached novelty, and had a lower HR during unfamiliarity. Behavioral differences between the two groups were maintained across childhood, as was a higher HR in inhibited children. How- ever, Pfeifer, Goldsmith, Davidson, and Rickman (2002) found that children changed in their levels of inhibition over the course of childhood. More research is needed to clarify the organization of children's behaviors over early development, whether there are changes in levels of fear or whether behaviors remain stable over early childhood. In order to gain a fuller picture, a multimethod approach investigating behavior and biological components of fear is needed.

\section{Fear Physiology}

Although most definitions of temperament suggest that there is a biological basis, developmental research has largely focused on observations of temperament in the laboratory and on parental reports. These measures are not without limitations (Kagan, 1994). Both behavioral and physiological measures of fear are needed in order to capture a reliable picture of individual differences in fear response (Lewis \& Ramsay, 1999).

Psychophysiological measures are useful in the study of infant temperament for a number of reasons. They are sensitive to changes in psychological state, and because they are nonverbal they are particularly useful when studying infants (Campos, 1976). Measures of HR and skin conductance level (SCL) have been carried out in infants and children (e.g., Burgess, Marshall, Rubin, \& Fox, 2003; Buss, Goldsmith, \& Davidson, 2005; Calkins \& Dedmon, 2000; Fracasso, Porges, Lamb, \& Rosenberg, 1994; Hernes et al., 2002; Provost \& Gouin-Decarie, 1979) and appear to be reliable, sensitive, and well validated physiological measures of temperament (Campos, 1976; Nigg, 2006; Strelau, 1998). However, psychophysiological assessments in infancy, specifically those involving the autonomic nervous system (ANS), are rarely carried out following emotion provocation (i.e., Laboratory Temperament Assessment Battery [Lab-TAB]; Goldsmith \& Rothbart, 1999), nor are they done across childhood (Fox, 1989; Scarpa, Raine, Venables, \& Mednick, 1997). The few studies in which psychophysiology was measured during emotional challenge did not involve infants (Calkins \& Dedmon, 2000; Kagan et al., 1987).

Research in developmental psychopathology has integrated the role of physiology in order to understand the development of risk pathways (Cicchetti \& Gunnar, 2008). It is important to investigate potential biological risk pathways to aggression, because antisocial and criminal adults often have their onset of deviant behavior in childhood (Loeber \& Stouthamer-Loeber, 1997). There is increasing evidence that aggressive children with persistent antisocial behavior are characterized by neurobiological problems (van Goozen, Fairchild, Snoek, \& Harold, 2007). Physiological dysregulation is common in children with internalizing and externalizing disorders (Bauer, Quas, \& Boyce, 2002). High resting HR and low HR variability predict more extreme fear and inhibition (Kagan, 1997) and more behavioral inhibition longitudinally (Kagan et al., 1984). By contrast, low resting HR has been proposed to be the best marker of antisocial behavior 
(Scarpa et al., 1997). Low baseline SCL has also been linked to externalizing behavior (Snoek, van Goozen, Matthys, Buitelaar, \& van Engeland, 2004; van Goozen, Matthys, CohenKettenis, Buitelaar, \& van Engeland, 2000) and to predict persistence of conduct disorder from childhood onward (Van Bokhoven, Matthys, van Goozen, \& van Engeland, 2005).

Much less is known about physiological reactivity during stress in very young children. The few available findings suggest that physiological reactivity is an important factor that not only reflects variation in temperament but also identifies those at risk for externalizing or internalizing behavioral problems in later life (Kagan, 1994).

There is evidence that physiological indices of fearlessness in early childhood predict later externalizing psychopathology. In a prospective study Raine, Venables, and Mednick (1997) found that children who had low HR at 3 years of age were rated as more aggressive at 11 years. Similarly, Gao, Raine, Venables, Dawson, and Mednick (2010) found that poor fear conditioning at age 3 predicted crime at age 23. According to the authors, these findings suggest that low levels of physiological arousal early in life impact on later behavior through a lack of fear associated with the low arousal. The consequence is that the individual fails to avoid situations, events, and contexts associated with punishment now and in the future; and this affects the development of their conscience. The question arises as to whether it is possible to identify predictors before the age of 3 . The work by Raine and colleagues highlights the importance of a multimethod approach, including the identification of early physiological profiles. At present we do not know whether behavioral and physiological responses to fear challenge are stable in children or whether there is differential stability in physiological and behavioral reactivity.

In the present research we were interested in (a) whether we would be able to identify fearless and fearful infants based on behavioral, physiological, and maternal report measures; (b) whether children would still be characterized as fearful or fearless 2 years later; and (c) which type of measure would be helpful in identifying these subgroups.

\section{Fear and the Development of Guilt}

In addition to understanding the role of early fear as a precursor to later psychopathology, it is important to investigate other emotions with which fear may be associated, especially moral emotions such as guilt. Guilt in children is defined as the feeling of distress following a mishap or transgression (Cole, Barrett, \& Zahn-Waxler, 1992; Kochanska, Gross, Lin, \& Nichols, 2002). Extremes in guilt proneness have been associated with later psychopathology. A lack of guilt proneness has been found to be positively related to externalizing behavior (Ferguson, Stegge, Miller, \& Olsen, 1999); aggression (Stuewig et al., 2010); and anger, hostility, and externalization of blame (Stuewig et al., 2010; Tangney \& Dearing, 2002). Moreover, children who experienced guilt were less likely to be arrested, convicted, and incarcerated as adolescents and more likely to practice safe sex and not abuse drugs (Tangney \& Dearing, 2002). Explanations for these adaptive effects focus on guilt requiring the individual to self-reflect and think about what they did and why (Stuewig et al., 2010). Individuals high in psychopathic traits fail to experience guilt (Raine, 1993).

Guilt is likely to be influenced by temperament (Kochanska, Barry, Jimenez, Hollatz, \& Woodard, 2009). Fearful temperament, in particular, has been proposed to be a critical component in the development of guilt and conscience. Guilt is said to develop once the child feels empathy for others and responsibility for themselves, with fearful children more likely to feel guilty following a transgression because of their increased sensitivity to punishment (Dienstbier, 1984; Gray, 1982; Kagan, 1998; Kochanska, 1993) and because they learn more easily to inhibit transgressions of moral behavior that are associated with punishment (Dienstbier, 1984). In contrast, children who are temperamentally fearless are less likely to learn from the distress associated with transgressing, not only because they are less responsive to the fear of punishment following a wrongdoing (Dienstbier, 1984) but also because they do not anticipate these feelings in future situations (Fowles, 1994; Lykken, 1995).

There are many inconsistencies in the developmental literature on guilt, including when guilt develops, how it differs from other moral emotions such as shame, and how it can be measured. Although there are large discrepancies in views about the age at which guilt develops, ranging from 8 years to 18 months (Ferguson, Stegge, \& Damhuis, 1991; Kagan, 1984; Kochanska, 1991), Kochanska (2001) argues that most developmental psychologists believe that in the second year of life young children begin to be clearly aware of their transgressions, misbehaviors, or substandard performances. Defined in this way, guilt has been identified as early as 22 months (Kochanska et al., 2002) or 24 months (Barrett, Zahn-Waxler, \& Cole, 1993).

A number of researchers believe that it is important to distinguish between guilt and shame early in development (Barrett et al., 1993; Ferguson et al., 1999), whereas others question whether this is possible (Kochanska et al., 2002). Kochanska (2001) believes that distinguishing guilt from shame at this point in development is premature, given the lack of understanding of very young children's responses to their transgressions. When children respond to transgressions by showing behavioral and affective signs of discomfort, this is regarded as an antecedent of future guilt (Kochanska et al., 2002). Barrett (1995) also claimed that in order to safely claim that a child experiences guilt, the toddler must display guilt-relevant behavior (e.g., facial/bodily distress, promoting reparation, acknowledgment/apology/confession for act) in a relevant context (i.e., just after a transgression happened). In the present research the term guilt will be used to describe a child's distress response to a mishap or transgression.

Most developmental research on guilt is with older children. It is difficult to relate empirical research on guilt in adolescents and adults to research on guilt in children. Guilt in 
adolescents and adults is often measured by self-report, with few studies using behavioral or physiological measures (TilghmanOsborne, Cole, \& Felton, 2010). Kochanska, DeVet, Goldman, Murray, and Putnam (1994) used observational and maternal reported measures of guilt and found only a modest convergence between these two methods. Given our limited understanding of the development of guilt, a multimethod approach is needed to fully capture guilt expression in young children (Tilghman-Osborne et al., 2010).

From the above it will be clear that little developmental research has investigated the physiological component of guilt. It seems reasonable to assume that individual differences in arousal will also play an important role in variations in guilt. Fowles and Kochanska (2000) investigated fear as a moderator of conscience in children at 32 months and 4 years using a multimethod approach. Fearful and SCL reactive children were more anxious later in childhood, and the behavioral and physiological measures of fear were almost equivalent in their role as moderators of socialization.

\section{Are Fear and Guilt Linked?}

It is widely accepted that the experience of guilt and the associated aversive arousal have an adaptive function. Diminished capacity to experience discomfort following a transgression may be a factor in poor avoidance learning and antisocial conduct (Lykken, 1995). If this is the case, children who experience guilt following a transgression would be less likely to transgress in the future (Dienstbier, 1984; Hoffman, 1983; Kochanska et al., 2002). Fearless children are by definition less likely to inhibit behavior because they experience less arousal following aversive events and are therefore less likely to experience guilt. The inability to assimilate these feelings over time will fail to act as a deterrent to misbehave in future.

Kochanska and colleagues (1994) have investigated the association between fearful temperament and early conscience development using maternal report and behavioral data. In an influential study, Kochanska et al. (2002) studied the association between observational guilt and fearfulness in 112 children at 22, 33, and 45 months; maternal ratings of guilt were collected at 22, 33, and 56 months. Fear and guilt were significantly correlated at every age of assessment, with fear at 33 months also being significantly associated with guilt at 45 months. Gender differences were also found, with girls displaying higher levels of guilt than boys at 33 and 45 months. These findings complement an earlier study finding a positive association between fearfulness in infancy and parent rated guilt at age 6 (Rothbart, Ahadi, \& Hershey, 1994).

These findings show that there are associations between fear and guilt in early childhood. Fear has been found to be associated with guilt across early childhood, with higher levels of fear being associated with higher levels of guilt and predicting later guilt. Kochanska and colleagues' research investigates children from the age of 2 years, using maternal report and observational data. At the moment, we do not know whether earlier assessments of fear would be asso- ciated with the later development of guilt or how fear physiology is associated with guilt.

In the present research we studied the stability of fear over the first 3 years of life using behavioral, maternal reported, and physiological assessments, as well as its associations with guilt. Fear and guilt may act to inhibit and prevent problem behaviors, such as aggression and antisocial behavior. As such, they are important emotions in our understanding of developmental psychopathology more generally.

\section{Method}

\section{Participants}

Participants and their families were recruited from local nurseries and play centers in Cardiff (Wales). The participants were 100 infants who first took part in our research around their first birthday. All participants were reinvited around their second birthday. Of those, 20 were unable to attend and a further 10 were unable to complete the final part of the study around the third birthday, although one mother-child dyad returned who had not taken part at age 2 . The main reasons for participants not completing the study were that the mothers had returned to work or had moved away from South Wales or we were unable to contact them. Overall, 70 children (36 boys, 34 girls) took part in the three waves of the study and are included in the current sample. The sample did not differ from the participants who dropped out in demographic characteristics (e.g., maternal age, family composition) or any of the study's dependent measures. The study was approved by the School of Psychology Research Ethics board at Cardiff University. The study was conducted in accordance with British Psychological Society guidelines and ethical protocol.

\section{Procedure of the experimental session}

The procedure took place in a child-friendly laboratory playroom. Mothers were asked to accompany their child to the laboratory where the children were assessed individually using several procedures designed to present an increasingly novel and challenging situation for the infants. The infant was given time to adjust to being in the laboratory and allowed to play with some age-appropriate toys while the procedure was explained to the mother. Once the mother thought the child had settled, ECG and SCL electrodes were placed on the child; baseline HR and SCL measures were taken when the mother and child were quietly playing together in the room for $3.5 \mathrm{~min}$. The fear procedure took approximately $3.5 \mathrm{~min}$. The mishaps paradigm lasted for approximately $2 \mathrm{~min}$ and was initiated after the child had recovered from the fear procedure. The mishaps/guilt paradigm was only used at the Year 3 assessment.

\section{Lab-TAB Fear Paradigm}

At each year of assessment, child fear and distress were assessed using the unpredictable mechanical toy component 
of the Lab-TAB (Goldsmith \& Rothbart, 1999). It closely followed the protocol of the Lab-TAB. However, for the purposes of the present study the mechanical toy dog used in Lab-TAB was replaced by a remote-controlled robot and the mother was asked to leave the room. An unfamiliar experimenter entered the room and placed the robot approximately $1.5 \mathrm{~m}$ away from the child, who was strapped into a child car seat. The experimenter made the robot approach the child, stopping approximately $15 \mathrm{~cm}$ from the child, while making movements with its arms and emitting noise. The robot then walked backward and stopped at the back of the room for about $10 \mathrm{~s}$ before moving forward again. This trial was repeated three times, in line with the Lab-TAB protocol.

\section{Coding}

The Lab-TAB's guidelines were followed for the behavioral coding of the episode, which was carried out using video recording of the session. It was important to gain clear and full frontal shots of the infant's face. Each of the three trials of robot approach and movement in front of the child was separated into three epochs (robot walk toward child, robot moving in front of child part one, robot moving in front of child part two). This created a total of nine epochs that were scored separately. A subgroup of the six Lab-TAB dimensions was used for scoring in this study in order to score the same distress parameters as the mishap procedure measuring guilt. Each epoch was scored on the following dimensions and scales: intensity of facial fear (0-3), intensity of distress vocalization (0-2), and intensity of bodily fear (0-3). A composite fear score was made from the sum of the three scores. The fear score using three dimensions of Lab-TAB fear correlated highly with the full Lab-TAB composite score (Year $1, r=.87$, $p<.01$; Year 2, $r=.91, p<.01$; Year 3, $r=.94, p<.01$ ).

To reduce the number of data, the highest score from a single epoch was used in the analyses to reflect the most intense behavioral score at a point in time. Scores ranged between 0 and 8 across all categories coded.

Four coders scored the episodes independently for $22 \%$ of the sample. Intracorrelation coefficients between coders ranged between 0.70 and 0.99 across the behavioral variables.

\section{Mishap guilt paradigm}

The mishaps paradigm was adapted from Kochanska et al. (2002). The task involved contrived transgressions or "mishaps." The experimenter presented the child with a tower, which she described as being her favorite toy and that she had made it herself. She told the child that she would share it with he/she, as long as they were very careful. Because the tower had been "rigged," the object fell apart as soon as the child began to handle it. The experimenter then said "Oh my. ..." with mild regret, and sat still in front of the child, with her face covered with her hands for $30 \mathrm{~s}$. The experimenter then asked three standard questions, "What happened?", "Who did it?", and "Did you do it?" The child was then told that it was not their fault and there had been a problem with the tower. She then presented another partially built tower and asked the child to help her make it. The experimenter reassured the child the damage had not been the child's fault and assumed responsibility for it.

\section{Coding}

The coding system used in the current study was adapted from Kochanska et al. (2002). To avoid ambiguity over the distinction of guilt and shame, the coding system focused on the level of distress to a mishap. The child's behavior was coded in 5-s epochs from when the tower fell to when the experimenter first told the child it was not his/her fault. The scoring reflects the level, or intensity, of the behavior. A subgroup of the five dimensions was used to measure the same parameters as distress during the fear procedure. Each epoch was scored on the following dimensions and scales: (a) bodily tension was scored on four categories: facial, posture, discomfort, and intense (if any behavior within the category was observed, the category would get a single score); this behavior was scored $0-3$, depending on how many categories were present (intense would score the epoch a 3); (b) facial tension was scored the same as bodily tension with four categories: eyes, eyebrows, and mouth intense ( $0-3)$; and vocal distress $(0-2)$. A composite guilt score was made from the sum of the three scores. The intensity score using three dimensions of distress correlated highly with the full mishaps distress score $(r=.94, p<.01)$.

\section{Data reduction}

In order to reflect the level of distress to guilt, an intensity score was given. The highest score from a single epoch was used. This score is regardless of when this peak response occurred or the duration of the procedure. The score ranged between 0 and 8 across all categories coded, with 8 showing the highest level of distress. The kappa coefficients were calculated for two raters for each coded behavior for $30 \%$ of the sample (bodily tension, $\kappa \mathrm{s}=0.69$; facial tension, $\kappa \mathrm{s}=0.83$; vocal distress, $\kappa \mathrm{s}=0.84$ ).

\section{Mother-reported fear (Year 1)}

Infant Behavior Questionnaire Revised. The Infant Behavior Questionnaire Revised (Gartstein \& Rothbart, 2003) assesses 14 domains of infant temperament, and the current study focused on the domain of "fear." The fear subscale consisted of 16 items (Cronbach $\alpha=0.88$ ). Each item was rated by the frequency with which it had been observed over the last week (or in some cases 2 weeks) on a 7-point scale from never (1) to always (7). There was also the option to respond "does not apply" to each item. The items were deliberately constructed so that parents rated observed behaviors and did not have to make comparisons or global judgments or recall past behaviors (Rothbart, 1981). 


\section{Mother-reported psychopathology (Years 2 and 3)}

The Child Behavior Checklist for Ages 1.5-5. The Child Behavior Checklist (Achenbach \& Rescorla, 2000) is a standardized form that rates diverse aspects of behavioral, emotional, and social functioning within a normal or clinical range. The mother rates 99 problem items as $0=$ not true of the child, $1=$ somewhat/sometimes true, and $2=$ very true/ often. The scores are organized in syndromes and grouped into internalized or externalized groupings. Of interest in the current study is the Iinternalizing score (Cronbach $\alpha=$ 0.89 ), computed by summing the scores from the four internalizing syndromes: emotionally reactive, anxious/depressed, somatic complaints, and withdrawn. Participants were identified as borderline or clinically internalized $(N=10)$ or within the normal range $(N=60)$ from their internalizing syndrome scales and grouping scale in either Year 2 or Year 3.

\section{Physiological reactivity}

The HR and SCL recording and analysis software programs were custom made using the PSYLAB program (PsyLab, 2007). Three ECG electrodes were attached to the child's back to measure HR in beats per minute. Two SCL electrodes were securely attached on the left foot (Edelberg, 1967). The electrodes placed on the participant were attached to a PSYLAB Stand Alone Monitor that is powered by $12-\mathrm{V}$ universal power units that run on any voltage between 100 and $250 \mathrm{~V}$ at 50-60 Hz. Measures of HR and SCL were taken throughout, recording mean levels at 30-s intervals.

\section{Missing data}

All 70 participants in the sample took part in every procedure, at all three assessments (Year 1 [Y1], Year 2 [Y2], and Year 3 [Y3]). A number of participants had missing data during these episodes, but none had all of the data missing during an entire episode. The missing data resulted from equipment malfunction or refusal to take part (missing data across variables: behavioral fear, $\mathrm{Y} 1=2, \mathrm{Y} 2=3, \mathrm{Y} 3=3$, guilt $=3$; $\mathrm{SCL}$ fear, $\mathrm{Y} 1=0, \mathrm{Y} 2=6, \mathrm{Y} 3=7$, guilt $=7$; HR fear, $\mathrm{Y} 1=0, \mathrm{Y} 2=6, \mathrm{Y} 3=9$, guilt $=9$ ). Data imputation was implemented using linear trend computation (Little \& Rubin, 1987).

\section{Data analysis}

We first investigated the associations between variables by examining the intercorrelations between fear variables and between fear and guilt variables. A stepwise (forward) regression was used to assess the unique contribution of $\mathrm{Y} 1$ and $\mathrm{Y} 2$ infant behavioral, physiological, and maternal reported fear to the explanation of Y3 fear and guilt.

SCL and HR were measured continuously during baseline (3.5 min, seven 30 -s periods) and the fear procedure (3.5 min, seven 30-s periods). An overall mean baseline ( $\mathrm{SCL}_{\text {base }}$, $\left.\mathrm{HR}_{\text {base }}\right)$ and fear $\left(\mathrm{SCL}_{\text {fear }}, \mathrm{HR}_{\text {fear }}\right)$ was calculated and used in subsequent analyses.

\section{Results}

Descriptive data are presented in Table 1 and the correlations between the variables in Table 2. Stepwise regressions examining predictors of later fear and guilt are presented in Table 3 and Table 4, respectively.

A repeated measures analysis of variance revealed a significant main effect of year of assessment for HR, $F(2,138)=$ $80.35, p<.001$, and SCL, $F(2,138)=25.84, p<.001$, and of condition for HR, $F(1,69)=118.95, p<.001$, and SCL, $F(1,69)=8.30, p<.01$. There was also a significant interaction between condition and year for HR, $F(1.72,118.48)=$ $53.83, p<.01$, and SCL, $F(2,138)=42.53, p<.001$. The significant effect of year means that levels of HR and SCL arousal generally decreased over the three assessments, whereas the main effect of condition shows that physiological arousal significantly increased from baseline to stress, indicating that fear was successfully induced. However, the effect of our fear manipulation was much more pronounced in Y2 (percentage increase from baseline to fear: $\mathrm{HR}=9.46 \%$, $\mathrm{SCL}=125.10 \%)$ compared to $\mathrm{Y} 1(\mathrm{HR}=3.74 \%, \mathrm{SCL}=$ $87.48 \%)$ and $\mathrm{Y} 3(\mathrm{HR}=3.60 \%, \mathrm{SCL}=57.39)$, as reflected by the significant interaction effect for both HR and SCL (see Table 1 for means). There was no main effect of year on behavioral fear, $F(2,138)=2.60, p=.08$, suggesting that observed behavioral fear remained stable over time.

Table 1. Descriptive statistics for all measures

\begin{tabular}{|c|c|c|c|c|}
\hline & \multicolumn{2}{|c|}{ Baseline } & \multicolumn{2}{|c|}{ Fear (Means) } \\
\hline & $M$ & $S D$ & $M$ & $S D$ \\
\hline \multicolumn{5}{|c|}{ Maternal-report fear } \\
\hline $\mathrm{Y} 1$ & - & - & 2.48 & .87 \\
\hline \multicolumn{5}{|l|}{ Behavioral fear } \\
\hline Y1 & - & - & 5.07 & 2.48 \\
\hline Y2 & - & - & 5.85 & 2.10 \\
\hline Y3 & - & - & 5.33 & 2.45 \\
\hline \multicolumn{5}{|l|}{ HR fear } \\
\hline Y1 & 136.43 & 12.15 & 141.34 & 15.78 \\
\hline Y2 & 121.86 & 9.74 & 133.11 & 13.97 \\
\hline $\mathrm{Y} 3$ & 113.72 & 9.84 & 117.72 & 14.77 \\
\hline \multicolumn{5}{|l|}{ SCL fear } \\
\hline Y1 & 10.87 & 8.04 & 16.80 & 11.71 \\
\hline Y2 & 6.75 & 4.31 & 11.66 & 6.64 \\
\hline Y3 & 7.35 & 3.83 & 9.11 & 3.64 \\
\hline \multicolumn{5}{|l|}{ Guilt } \\
\hline Behavioral & - & - & 4.30 & 2.01 \\
\hline HR & - & - & 108.99 & 9.02 \\
\hline SCL & - & - & 10.35 & 4.27 \\
\hline
\end{tabular}

Note: (—) No measurement taken. Y1, Year 1; Y2, Year 2; Y3, Year 3; HR, heart rate; SCL, skin conductance level. 


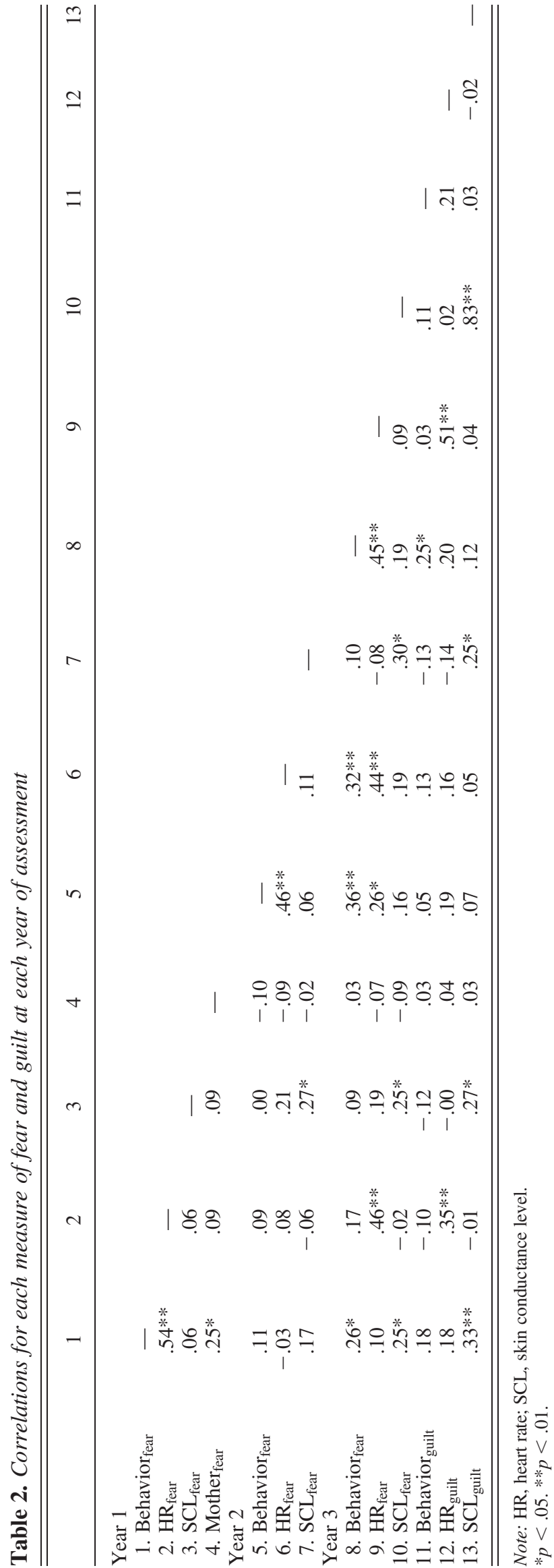

Fear from Y1 to Y3: Associations across measures

Associations between all measures of fear at each age of assessment are presented in Table 2. Y1 behavioral fear was associated with $\mathrm{Y} 1 \mathrm{HR}_{\text {fear }}(r=.54, p<.01)$ and $\mathrm{Y} 1$ maternal reported fear $(r=.25, p<.05)$. $\mathrm{HR}_{\text {fear }}$ and behavioral fear continued to have a positive association in Y2 $(r=.46, p$ $<.01)$ and $\mathrm{Y} 3(r=.45, p<.01)$. $\mathrm{SCL}_{\text {fear }}$ was not associated with any other fear measure at any of the assessments.

The measures of behavioral fear were associated between $\mathrm{Y} 1$ and $\mathrm{Y} 3(r=.26, p<.05)$ and between $\mathrm{Y} 2$ and $\mathrm{Y} 3(r=$ $.36, p<.01)$ but not between $\mathrm{Y} 1$ and $\mathrm{Y} 2(r=.11, p=.37)$. Similarly, the measures of $\mathrm{HR}_{\text {fear }}$ were associated between $\mathrm{Y} 1$ and $\mathrm{Y} 3(r=.46, p<.01)$ and between $\mathrm{Y} 2$ and $\mathrm{Y} 3(r=.44, p$ $<.01)$, but not between $\mathrm{Y} 1$ and $\mathrm{Y} 2(r=.08, p=.51)$. Positive associations were found for $\mathrm{SCL}_{\text {fear }}$ across all ages of assessment, from $\mathrm{Y} 1$ to $\mathrm{Y} 2(r=.27, p<.05)$, from $\mathrm{Y} 1$ to $\mathrm{Y} 3(r$ $=.25, p<.05)$, and from $\mathrm{Y} 2$ to $\mathrm{Y} 3(r=.30, p<.05$; see Table 2).

\section{Gender}

Gender differences for all study variables were investigated using Fisher $r$ to $z$ transformations. There were no significant differences between the correlation coefficients for boys and for girls. Gender was not considered in further analyses.

\section{Early fear as a predictor of fear in $Y 3$}

Table 3 summarizes the results of a series of regression analyses, highlighting the predictors of each measure of fear. In order to test whether early measures of fear predicted later fear, stepwise (forward) regressions were used for each measure of fear. At Step 1 the Y1 assessment of the dependent measure in question was included as a predictor variable. At Step 2 the other Y1 measures of fear were entered. At Step 3 the Y2 assessment of the dependent measure in question was included as a predictor variable.

Behavioral fear in Y3. Y1 behavioral fear positively predicted Y3 behavioral fear. This association was reduced to nonsignificance when the other $\mathrm{Y} 1$ variables were entered as predictors. Y2 behavioral fear positively predicted Y3 behavioral fear over and above all Y1 measures. None of the Y1 physiological measures of fear predicted Y3 behavioral fear.

$Y 3 H R_{\text {fear }}$. Y1 $\mathrm{HR}_{\text {fear }}$ significantly predicted $\mathrm{Y} 3 \mathrm{HR}_{\text {fear }}$, and this remained the case after the introduction of the other $\mathrm{Y} 1$ variables and the $\mathrm{Y} 2$ measure of $\mathrm{HR}_{\text {fear }}$. This shows that infants who had a higher $\mathrm{HR}_{\text {fear }}$ in $\mathrm{Y} 1$ and $\mathrm{Y} 2$ continued to have a higher $\mathrm{HR}_{\text {fear }}$ in $\mathrm{Y} 3$. Y1 behavioral fear, $\mathrm{SCL}_{\text {fear }}$, or maternal report of fear did not predict $\mathrm{Y} 3 \mathrm{HR}_{\text {fear }}$.

Y3 SCL $L_{\text {fear }}$. Y1 SCL fear predicted Y3 SCL fear after controlling for the influence of the other Y1 measures. This association was reduced to nonsignificance with the introduction of $\mathrm{Y} 2$ 
Table 3. Summary of all stepwise regression analysis for variables predicting behavioral, $H R$, and SCL fear in $Y 3(N=70)$

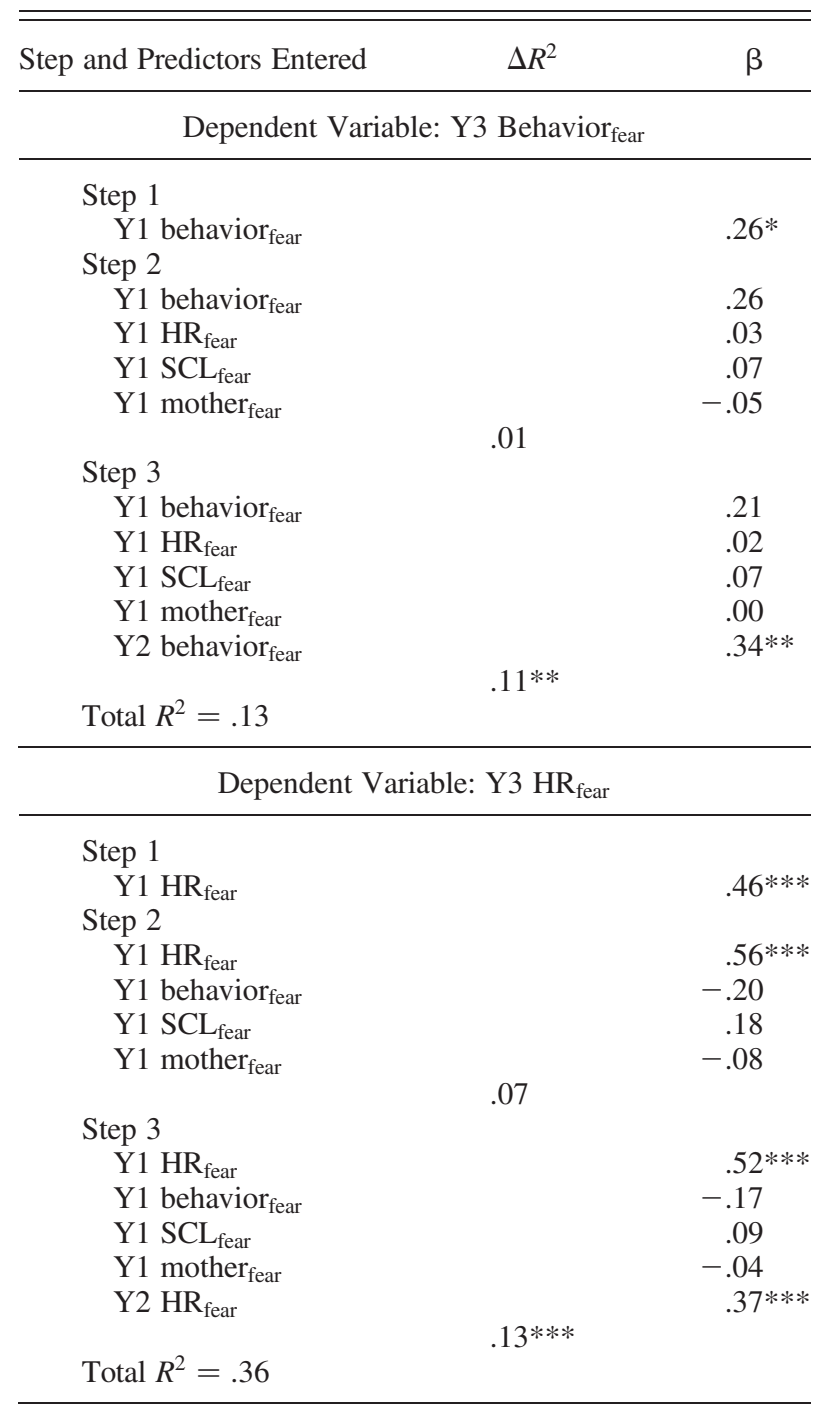

\begin{tabular}{|c|c|c|}
\hline \multicolumn{3}{|c|}{ Dependent Variable: Y3 SCL fear } \\
\hline Step 1 & & \\
\hline $\mathrm{Y} 1 \mathrm{SCL}_{\text {fear }}$ & & $.25^{*}$ \\
\hline Step 2 & & \\
\hline Y1 SCL fear & & $.26^{*}$ \\
\hline Y1 behavior fear & & $.43 * *$ \\
\hline $\mathrm{Y} 1 \mathrm{HR}_{\mathrm{fear}}$ & & -.25 \\
\hline Y1 mother $r_{\text {fear }}$ & & -.20 \\
\hline \multicolumn{3}{|c|}{$.13^{*}$} \\
\hline Step 3 & & \\
\hline Y1 SCL $L_{\text {fear }}$ & & .21 \\
\hline Y1 behavior ${ }_{\text {fear }}$ & & $.37 *$ \\
\hline $\mathrm{Y} 1 \mathrm{HR}_{\mathrm{fear}}$ & & -.21 \\
\hline Y1 mother $_{\text {fear }}$ & \multirow[b]{3}{*}{.02} & -.18 \\
\hline Y2 SCL fear & & .16 \\
\hline Total $R^{2}=.16$ & & \\
\hline
\end{tabular}

Note: HR, heart rate; SCL, skin conductance level, Y3, Year 3; Y1, Year 1; Y2, Year 2.

$* p<.05 . * * p<.01 . * * * p<.001$.
Table 4. Summary of all stepwise regression analyses for variables predicting HR and SCL guilt in $Y 3(N=70)$

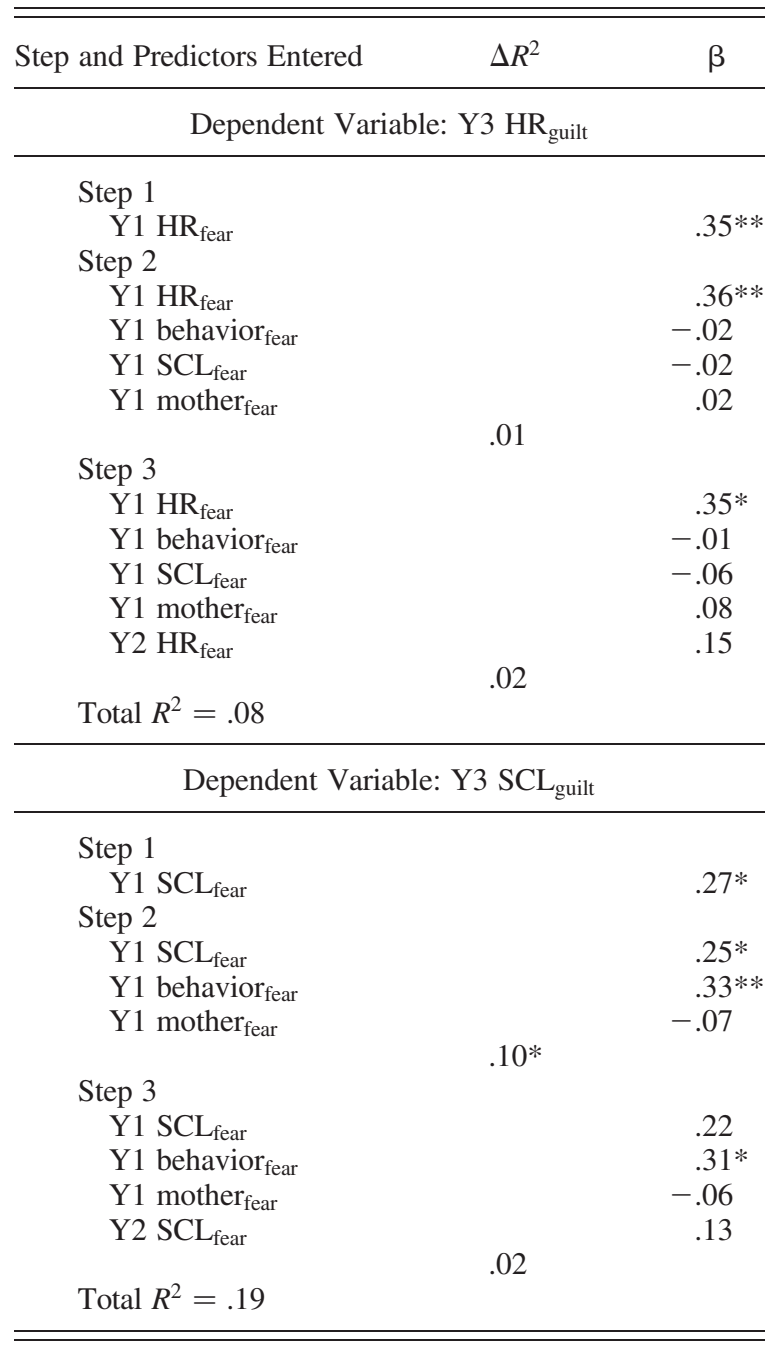

Note: HR, heart rate; SCL, skin conductance level; Y3, Year 3; Y1, Year 1; Y2 Year 2.

$* p<.05 .{ }^{* *} p<.01 . * * * p<.001$.

$\mathrm{SCL}_{\text {fear }}$. Infants with higher levels of behavioral fear in $\mathrm{Y} 1$ had higher levels of Y3 SCL arousal during fear. This association remained the largest after the introduction of other Y1 variables and Y2 SCL.

\section{Associations between fear and guilt}

Y3 behavioral measures of fear were associated with Y3 guilt, and Y3 physiological measures of fear were also positively associated with Y3 guilt (see Table 2), suggesting that these are related constructs. However, these associations were only within the type of measure: behavior $(r=.25, p<.05), \mathrm{HR}(r$ $=.51, p<.01)$, and SCL $(r=.83, p<.01)$. There were no associations between different types of measure in Y3. There were no significant correlations between $\mathrm{Y} 1$ behavioral or 
physiological measures of fear and Y3 behavioral guilt. Behavioral guilt was not included in further analyses.

\section{Early fear as a predictor of guilt}

Table 4 summarizes the results of a series of regression analyses, highlighting the predictors of each type of measure of Y3 guilt. In order to test whether measures of fear in Y1 and/or Y2 predicted Y3 guilt, stepwise (forward) regressions were used.

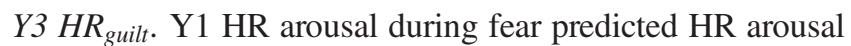
during guilt in Y3.

$S C L_{\text {guilt }}$. Y1 SCL fear predicted SCL arousal during guilt in Y3. Regression diagnostics revealed that the relationship between behavioral fear and $\mathrm{HR}_{\text {fear }}$ at $\mathrm{Y} 1$ could be biasing the model (from inspection of the variance inflation factor). Stepwise regressions were conducted excluding Y1 HR fear. The association between $\mathrm{Y} 1 \mathrm{SCL}_{\text {fear }}$ and $\mathrm{SCL}_{\text {guilt }}$ was reduced to nonsignificance with the introduction of $\mathrm{Y} 2 \mathrm{SCL}_{\mathrm{fear}}$. Infants with higher levels of behavioral fear in Y1 had higher levels of Y3 SCL arousal during guilt. This association remained significant after the introduction of other $\mathrm{Y} 1$ variables and Y2 SCL.

Taken together, the results show that measures of HR and SCL fear arousal in Y1 predicted guilt responses in toddlers. Year 2 measures of fear arousal did not predict Y3 guilt.

\section{$H R$ and behavioral fear in infancy and later internalizing psychopathology}

Children who were rated by their mothers as clinically internalized at age 3 had significantly higher levels of HR during baseline and fear in Y1 ( $\mathrm{HR}_{\text {baseline }}, U=171, z=-2.17, p<$ $\left..05 ; \mathrm{HR}_{\mathrm{fear}}, U=162.5, z=-2.31, p<.05\right)$. Internalized children had significantly higher $\mathrm{HR}_{\text {baseline }}(M=143.16, \mathrm{SD}=$ 7.69) and $\mathrm{HR}_{\text {fear }}(M=152.74, S D=14.81)$ in $\mathrm{Y} 1$ than those in the normal range $\left(\mathrm{HR}_{\text {baseline }}, M=134.72, S D=11.03\right.$; $\left.\mathrm{HR}_{\text {fear }}, M=139.44, S D=15.23\right)$. Clinically internalized children also had higher behavioral fear scores $(M=6.5$, $S D=1.72)$ in $\mathrm{Y} 1$ than those in the normal range $(M=$ $4.83, S D=2.52)$; however, this difference was only marginally significant $(U=193.5, z=-1.81, p=.07)$.

\section{Discussion}

This study had four aims: (a) to investigate the associations among behavioral, maternal reported, and physiological parameters of fear in infants; (b) to examine the stability of fear from infancy to early childhood; (c) to find out whether fear and guilt are associated; (d) to explore whether early fear predicts later guilt; and (e) to find out whether internalized toddlers differ from normal toddlers on measures taken in infancy.
We began by examining the associations between different measures of fear. The levels of HR and SCL increased significantly from baseline during fear induction, confirming that the procedure used in the current study was successful in arousing the ANS. We predicted positive associations between behavioral and physiological fear, such that behaviorally fearless children would exhibit lower levels of ANS arousal during fear challenge. This prediction was partly supported: although at each year of assessment behavioral fear and $\mathrm{HR}_{\mathrm{fear}}$ were significantly positively associated, this was not the case for SCL. Fowles, Kochanska, and Murray (2000) found associations between SCL and fear behavior at 4 years, but not earlier. In the present study the association between SCL and fearfulness strengthened with each assessment ( $r=.06-.19)$, suggesting that this association might develop across time.

HR and SCL are different components of the ANS; SCL is controlled solely by the sympathetic nervous system, whereas $\mathrm{HR}$ is the result of the combined action of the sympathetic nervous system and parasympathetic nervous system. Particularly important in this respect is the vagal control of the heart (i.e., vagal tone; Lovallo, 1997). HR and SCL were not associated in the present data, suggesting that although they both independently index arousal responses to fear, they reflect different components of fear. It is worth noting that the nonassociation of HR and SCL is a well-known phenomenon in research on antisocial behavior (even though antisocial or conduct disordered individuals are characterized by both low HR and low SCL; e.g., Raine, 1993; Van Goozen et al., 2000) and emotion research more generally. Fear is a complex construct, and the findings from the present study underscore this once more. It is only through the continued use of multimethod approaches to testing that we can begin to understand it.

In Y1 mothers' reports of infant fear corresponded with independently observed fear, but not with physiological fear. This indicates that different observers may agree about what they see, but what they see is not necessarily what the child experiences. Thus, mothers who rated their child as having a fearful temperament did not necessarily have a child who became highly aroused during fear. Kagan (1994) argues that maternal reports are too subjective, with mothers reporting their impressions of the child, which are likely influenced by their expectations of their child's temperament. Maternal report does not appear to be the best measure of a child's fear experience.

Our next aim was to assess the associations of fear from infancy up to age 3. Although HR and SCL baseline and stress levels decreased significantly over time, physiological fear reactivity was significantly higher in Y2, showing that physiological fear is not stable over time. This pattern of increased fearfulness in Y2 was not reflected in significantly greater behavioral fear, although observed fear distress was somewhat higher in Y2 $(M=5.85)$ than in $\mathrm{Y} 1(M=5.07)$ and Y3 $(M=5.33)$. Individual differences in fearfulness were found to be associated, however, as reflected in the 
positive and significant correlations between the measures over time. Fearless infants continue to be fearless toddlers.

In addition to the associations between different types of measures, we were interested in whether individual differences in early fear were predictive of later fear. Behavioral fearlessness in infancy predicted behavioral fearlessness and low SCL fear arousal in Y3, and low HR fear arousal in infancy predicted low HR fear arousal in Y3. All measures in infancy predicted their counterpart measures in Y3, with behavioral fear also predicting across measures in Y3. The inclusion of the equivalent measure of fear at $\mathrm{Y} 2$ enabled us to include this more temporally proximal measure in the analysis and to observe whether Y1 measures continued to have predictive utility. This was largely the case, especially for physiological fear. However, with the inclusion of other estimates of fear in Y1 and the Y2 behavioral measure of fear, behavioral fear in Y1 was no longer associated with behavioral fear in Y3. Overall, the inclusion of Y2 assessments shows that even after controlling for more proximal assessments, Y1 indices play a role in the explanation of variance in individual differences at Y3.

Kochanska and colleagues (2002) found that fearfulness and guilt were associated at each of their assessments. We therefore predicted that fearful individuals would experience and exhibit more guilt and, conversely, that fearless individuals would have lower levels of guilt. We assessed guilt in Y3, so we first were interested in the concurrent association with fear in Y3. Behavioral and physiological measures of fear and guilt were found to be positively associated within the type of measure, confirming this prediction. Toddlers exhibiting less behavioral or physiological fear also showed less distress and experienced less arousal during the mishap guilt procedure.

We next predicted that fear in infancy would predict guilt proneness in toddlers. To our knowledge, there is no previous study investigating this relationship using behavioral and physiological measures and few studies have examined this association from infancy. Our findings not only confirmed the existence of a concurrent association between fear and guilt but also showed some evidence that fear in infancy was predictive of guilt 2 years later. Such an association was found for HR and SCL, but not for behavioral fear, although behavioral fear in infancy predicted SCL arousal during guilt.

Behavioral fear in infancy predicted Y3 behavioral fear, which was in turn strongly associated with behavioral guilt. However, contrary to our predictions, behavioral fear in infancy was not correlated with behavioral guilt in Y3. We can infer that although behavioral measures of fear and guilt are associated at the same stage of development, earlier behavioral fear is not predictive of later behavioral guilt. It is worth noting that Kochanska and colleagues (2002) also only found associations between concurrent measures of fear and guilt.

With increasing age, children are better able to engage in emotion regulation and therefore to inhibit or mask an overt expression of negative affect and to avoid intense emotional expressions (Kochanska et al., 2002). It may therefore be that fear- and guilt-prone toddlers, the ones who become aroused when challenged, modulate their expression of their feelings during and following a transgression, resulting in a weaker association between infant fear and toddler guilt.

In contrast to fear, a basic emotion that is present from birth and does not necessarily entail a lot of cognitive processing, guilt is complex and requires a higher level of cognitive understanding. It is possible that guilt is still developing at the age of 3 and therefore that the stability of the relation between behavioral expressions of fear and guilt only emerges later. It is interesting, however, that physiological fear arousal in infancy predicted physiological arousal to guilt in Y3, suggesting that a child's arousal during these emotions draws on the same underlying mechanism.

Our findings indicate that the physiological response develops first and the cognitive processes follow. This concurs with current theories of emotion. According to Izard (1992), the brain mechanisms of the emotion systems mature earlier than some of the mechanisms (e.g., hippocampus) required for contextual learning and for autobiographical and declarative memory. He conceived emotion experience as a "feeling state" that does not require cognitive mediation and suggested that emotion processes can operate independently of cognition. Emotions can be activated by a subcortical (thalamoamygdala) pathway that can operate independently of the neocortex and therefore independently of any type of cognition requiring cortical processing or integration (LeDoux, 1987). Sympathetic arousal, an index of emotional behavior released by the amygdala, can be seen as an indicator of an intervening feeling-motivational state generated by the subcortical pathway (Izard, 1992).

Our data show that the discomfort that fearful children experience during fear-arousing situations appears to bleed into other negative emotions such as guilt, and the proneness to experience these feelings seems to be relatively stable across early childhood. This is important because the subjective discomfort associated with fear and guilt encourages children to learn to avoid these situations in the future (Kochanska et al., 2002), perhaps being influenced by somatic markers (Damasio, 1996). The present evidence suggests that the feelings associated with fear and guilt (insofar as these are captured by physiological measures) are relatively stable over time but that the overt expression of these emotions is less stable, being consistent within but not across time. This highlights the importance of investigating multiple components of emotions.

The inclusion of the more temporally proximal counterpart measure of fear in Y2 did not play a role in the explanation of the variance in levels of guilt proneness. Fear in infancy alone predicted guilt proneness in toddlers, within and across measures. That Y1 measures were significant predictors even when controlling for Y2 highlights the importance of starting to assess these variables in the first year. Y2 measures may be less predictive than Y1 measures 
because the general tendency for children to score more highly on Y2 measures of fear arousal may have masked the relationship with guilt.

The present study investigated variations in fear in normally developing children to establish whether it is possible to identify risk pathways from an early age. Within a typically developing sample extremes can be identified and may even be classified in the clinical range. Although we predicted that extremes in early fearfulness would be associated with later internalizing problems, little is known about the early risk factors for this association. We found that a subgroup of internalized toddlers showed significantly higher levels of HR during baseline and fear in infancy. These infants also showed more behavioral distress, which is consistent with previous findings (Kagan et al., 1984, 1987). These findings further underline the salience of investigating infant emotion and show that risk factors for later psychopathology can be identified at an early age.

Fearful temperament not only plays a role in children's expression of emotion but may also affect infants' developing sense of self-efficacy. Young children's expression of positive and negative emotions may play a significant role in their development of social relationships. Positive emotions appeal to social partners and seem to facilitate the formation of relationships, whereas problematic management or expression of negative emotions leads to difficulty in social relationships (Denham \& Weissberg, 2004).

Between birth and the end of toddler age, children develop the foundation for all social interactions. They learn to feel and identify a wide variety of emotions, and they experience a wide range of social interactions. We already mentioned that infants experience and express emotions before they fully understand them. In learning to recognize, label, manage, and communicate their emotions children build skills that connect them with their family and later with their peers and others in their environment. These emerging capacities help young children to become competent in increasingly complex social interactions and to reap the benefits of social support crucial to healthy human development and functioning.

Prior studies have found gender differences in fear and guilt, finding girls to be more fearful and guilt prone (Kochanska et al., 1994, 2002), leading us to anticipate gender differences in fear and guilt. However, we found no differences between boys and girls on any of our study variables at any age of assessment. It may be that gender differences in fear and/or guilt only become apparent after age 3 . It is also possible that the power to detect gender differences in the current study was too low because of the relatively modest sample size. Future research should aim to investigate gender differences in fear and guilt in larger samples.

Developmental investigations into risk pathways for later psychopathology should not wait until middle childhood (Cicchetti \& Toth, 2009). The current study highlights the value of investigating emotion development from infancy onward and shows that fearfulness in infancy is stable and predicts fear and guilt in toddlerhood. Fearfulness and high levels of guilt have been linked to internalizing problems (Biederman et al., 1990, 1993; Harder, 1995; O’Connor, Berry, Weiss, \& Gilbert, 2002; Schwartz et al., 1999; ZahnWaxler, Kochanska, Krupnick, \& McKnew, 1990). Conversely, fearlessness and deficient guilt experience have long been linked to externalizing problems, including aggression and antisocial behavior (Gao et al., 2010; Raine et al., 1997). Although relationships between emotionality and later psychopathology have been confirmed in children, our results suggest that some patterns are already established in infancy, highlighting the early development of risk pathways.

The current study adopted a prospective, multimethod approach and by doing so showed that physiology is an important and stable measure of individual differences in children's temperament. Fearless infants not only had lower levels of ANS arousal across the years of assessment but also showed less fear behavior and physiological reactivity to fear and guilt 2 years later. Research in the area of developmental psychopathology should not wait until children have developed emotional and behavioral problems. If we seek to understand pathological development and to prevent problems from developing, we need to know when and how emotions develop and when temperament becomes stable. By showing that individual differences in fearful temperament are associated from the first year of life and predictive of later fear and guilt, the present study strongly suggests that the first 3 years of life represent a crucial period when important systems that are involved in the experience and expression of emotions are established and children become emotionally "hardwired." By investigating normal development from infancy onward we can extend our understanding of developmental trajectories and begin to identify risk pathways that extend beyond early childhood.

The present study highlights the role of individual differences in physiology and fearful temperament at a time before important external factors also begin to affect emotion development (e.g. peers and school, or effects of smoking, exercise, and puberty on ANS functioning; Raine et al., 1997). Another important factor in early emotion development is the quality of the parent-child relationship. The period of our study coincides with the theorized development of attachment relationships with primary caregivers, and the research paradigm shared some of its features with the Strange Situation procedure (Ainsworth, Blehar, Watrers, \& Wall, 1978; e.g., a separation and reunion between parent and child, the presence of a stranger, exposure to a potential stressor and a laboratory setting). Future studies may wish to study features of the child's social world (including parenting behavior and attachment security) as part of investigations into early temperament (Blandon et al., 2010), emotion regulation (Bowlby, 1969; Kim \& Cicchetti, 2010), risk pathways (Barker, Oliver, Viding, Salekin, \& Maughan, 2011), and moral development (Kochanska, 1991; Kochanska, Barry, Aksan, \& Boldt, 2008).

Similar developmental pathways to the ones identified in this study have been found in later life. Fearless individuals 
display low levels of ANS arousal to fear (Gao et al., 2010; Quay, 1965; Raine, 1993) and are seen to experience low levels of guilt (Kochanska et al., 2002), whereas fearful individuals display higher levels of physiological fear (Kagan, 1998; Kagan et al., 1987) and higher levels of guilt (Kochanska et al., 2002). These profiles in normal healthy samples can extend into psychopathological patterns, with extremely fearful and guilt-prone children showing anxious and depressive tendencies subsequently (Biederman et al., 1990, 1993; Harder, 1995; Zahn-Waxler et al., 1990) and fearless and low guilt-prone individuals being at risk for de-

\section{References}

Achenbach, T. M., \& Rescorla, L. A. (2000). Manual for the ASEBA preschool forms and profiles. Burlington, VT: University of Vermont, Department of Psychiatry.

Ainsworth, M. D., Blehar, M. C., Watrers, E., \& Wall, S. (1978). Patterns of attachment: A psychological study of the strange situation. Hillsdale, NJ: Erlbaum.

Barker, E. D., Oliver, B. R., Viding, E., Salekin, R. T., \& Maughan, B. (2011). The impact of prenatal maternal risk, fearless temperament and early parenting on adolescent callous-unemotional traits: A 14-year longitudinal investigation. Journal of Child Psychology and Psychiatry, 52, $878-888$.

Barrett, K. C. (1995). The origins of guilt in early childhood. In J. Bybee (Ed.), Guilt and children (pp. 75-90). New York: Academic Press.

Barrett, K. C., Zahn-Waxler, C., \& Cole, P. M. (1993). Avoiders vs. amenders: Implications for the investigation of guilt and shame during toddlerhood? Cognition \& Emotion, 7, 481-505.

Bauer, A. M., Quas, J. A., \& Boyce, W. T. (2002). Associations between physiological reactivity and children's behavior: Advantages of a multisystem approach. Developmental and Behavioral Pediatrics, 23, 102113.

Biederman, J., Rosenbaum, J. F., Bolduc-Murphy, E. A., Faraone, S. V., Chaloff, J., Hirshfield, M. A., et al. (1993). A 3-year follow-up of children with and without behavioral inhibition. Journal of the American Academy of Child \& Adolescent Psychiatry, 32, 814-821.

Biederman, J., Rosenbaum, J. F., Hirshfield, D. R., \& Faraone, S. V. (1990). Psychiatric correlates of behavioral inhibition in young children of parents with and without psychiatric disorders. Archives of General Psychiatry, 47, 21-26.

Blair, R. J. R. (1997). Moral reasoning and the child with psychopathic tendencies. Personality and Individual Differences, 22, 731-739.

Blandon, A. Y., Calkins, S. D., Keane, S. P., \& O'Brien, M. (2010). Contributions of child's physiology and maternal behavior to children's trajectories of temperamental reactivity. Developmental Psychology, 46, 10891102.

Bowlby, J. (1969). Attachment and loss (Vol. 1). New York: Basic Books.

Burgess, K. B., Marshall, P. J., Rubin, K. H., \& Fox, N. A. (2003). Infant attachment and temperament as predictors of subsequent externalizing problems and cardiac physiology. Journal of Child Psychology and Psychiatry, 44, 819-831.

Buss, A. H., \& Plomin, R. (1984). Temperament: Early developing personality traits. Hillsdale, NJ: Erlbaum.

Buss, K. A., Goldsmith, H. H., \& Davidson, R. J. (2005). Cardiac reactivity is associated with changes in negative emotion in 24-month-olds. Developmental Psychobiology, 46, 118-132.

Calkins, S. D., \& Dedmon, S. E. (2000). Physiological and behavioral regulation in two-year-old children with aggressive/destructive behavior problems. Journal of Abnormal Child Psychology, 28, 103-127.

Campos, J. J. (1976). Heart rate: A sensitive tool for the study of emotional development in the infant. In L. P. Lipsitt (Ed.), Developmental psychobiology: The significance of infancy (pp. 1-34). Hillsdale, NJ: Erlbaum.

Cicchetti, D., \& Gunnar, M. R. (2008). Integrating biological measures into the design and evaluation of preventive interventions. Development and Psychopathology, 20, 737-743.

Cicchetti, D., \& Toth, S. L. (2009). The past achievements and future promises of developmental psychopathology: The coming of age of a disci- veloping callous and unemotional (i.e., psychopathic) personalities and exhibiting antisocial and aggressive behavior (Blair, 1997). This is not to say that these developmental patterns in infancy are fixed and will inevitably develop into these more extreme profiles. Children are resilient and continue to develop throughout their lives. However, we have shown that there is some degree of stability over time from infancy onward. Early detection of more extreme variations in fear and guilt proneness in very young children may ultimately have implications for the prevention of both internalizing and externalizing disorders.

pline. Journal of Child Psychology and Psychiatry and Allied Disciplines, 50, 16-25.

Colder, C. R., Mott, J. A., \& Berman, A. S. (2002). The interactive effects of infant activity level and fear on growth trajectories of early childhood behavior problems. Development and Psychopathology, 14, 1-23.

Cole, P. M., Barrett, K. C., \& Zahn-Waxler, C. (1992). Emotion displays in two-year-olds during mishaps. Child Development, 63, 314-324.

Damasio, A. R. (1996). The somatic marker hypothesis and the possible functions of the prefrontal cortex. Philosophical Transactions of the Royal Society B: Biological Sciences, 351, 1413-1420.

Denham, S., \& Weissberg, R. P. (2004). Social-emotional learning in early childhood: What we know and where to go from here? In E. Chesebrough, P. King, M. Bloom, \& T. P. Gulotta (Eds.), A blueprint for prosocial behavior in early childhood. New York: Kluwer Academic/Plenum Press.

Derryberry, D., \& Rothbart, M. K. (2001). Early temperament and emotional development. In A. F. Kalverboer \& A. Gramsbergen (Eds.), Handbook of brain and behavior in human development (pp. 967-988). Dordrecht: Kluwer Academic.

Dienstbier, R. A. (1984). The role of emotion in moral socialization. In C. Izard, J. Kagan, \& R. B. Zajonc (Eds.), Emotions, cognitions and behavior (pp. 484-513). New York: Cambridge University Press.

Edelberg, R. (1967). Methods in psychophysiology. Baltimore, MD: Williams \& Wilkins.

Ferguson, T. J., Stegge, H., \& Damhuis, I. (1991). Children's understanding of guilt and shame. Child Development, 62, 827-839.

Ferguson, T. J., Stegge, H., Miller, E. R., \& Olsen, M. E. (1999). Guilt, shame, and symptoms in children. Developmental Psychology, 35, 347-357.

Fowles, D. C. (1994). A motivational theory of psychopathology. In W. Spaulding (Ed.), Nebraska Symposium on Motivation: Vol. 41. Integrated views of motivation and emotion (pp. 181-228). Lincoln, NE: University of Nebraska Press.

Fowles, D. C., \& Kochanska, G. (2000). Temperament as a moderator of pathways to conscience in children: The contribution of electrodermal activity. Psychophysiology, 37, 788-795.

Fowles, D. C., Kochanska, G., \& Murray, K. (2000). Electrodermal activity and temperament in preschool children. Psychophysiology, 37, 777-787.

Fox, N. A. (1989). Psychophysiological correlates of emotional reactivity during the first year of life. Developmental Psychology, 25, 364-372.

Fracasso, M. P., Porges, S. W., Lamb, M. E., \& Rosenberg, A. A. (1994). Cardiac activity in infancy: Reliability and stability of individual differences. Infant Behavior and Development, 17, 277-284.

Frick, P. J. (2004). Integrating research on temperament and childhood psychopathology: Its pitfalls and promise. Journal of Clinical Child and Adolescent Psychiatry, 33, 2-7.

Gao, Y., Raine, A., Venables, P. H., Dawson, M. E., \& Mednick, S. A. (2010). Association of poor childhood fear conditioning and adult crime. American Journal of Psychiatry, 167, 56-60.

Gartstein, M. A., \& Rothbart, M. K. (2003). Studying infants temperament via the Revised Infant Behavior Questionnaire. Infant Behavior \& Development, 26, 64-86.

Goldsmith, H. H., \& Rothbart, M. K. (1999). The Laboratory Temperament Assessment Battery; Description of procedures. Locomotor version. Unpublished manuscript. 
Gray, J. A. (1982). The neuropsychology of anxiety. London: Oxford University Press.

Harder, D. W. (1995). Shame and guilt assessment, and relationships of shame- and guilt-proneness to psychopathology. In J. P. Tangney \& K. W. Fischer (Eds.), Self-conscious emotions the psychology of shame, guilt, embarrassment, and pride (pp. 368-392). New York: Guilford Press.

Hernes, K. G., Mørkrid, L., Fremming, A., Ødegården, S., Martinsen, Ø. G., \& Storm, H. (2002). Skin conductance changes during the first year of life in full-term infants. Pediatric Research, 52, 837-843.

Hirshfield, D. R., Biederman, J., Brody, L., Faraone, S. V., \& Rosenbaum, F. (1997). Expressed emotion toward children with behavioral inhibition: Association with maternal anxiety disorder. Journal of the American Academy of Child \& Adolescent Psychiatry, 36, 910-917.

Hirshfield-Becker, D. R., Biederman, J., Calltharp, S., Rosenbaum, E. D., Faraone, S. V., \& Rosenbaum, J. F. (2003). Behavioral inhibition and disinhibition as hypothesized precursors to psychopathology: Implications for paediatric bipolar disorder. Biological Psychiatry, 53, 985999.

Hoffman, M. L. (1983). Affective and cognitive processes in moral internalization. In E. T. Higgins, D. Ruble, \& W. Hartup (Eds.), Social cognition and social development: A socio-cultural perspective (pp. 236-274). New York: Cambridge University Press.

Izard, C. E. (1992). Basic emotions, relations among emotions, and emotioncognition relations. Psychological Review, 99, 561-566.

Kagan, J. (1982). Heart rate and heart rate variability as signs of temperamental dimension in infancy. In C. E. Izard (Ed.), Measuring emotions in infants and children (pp. 38-66). Cambridge: Cambridge University Press.

Kagan, J. (1984). The nature of the child. New York: Basic Books.

Kagan, J. (1994). Galen's prophecy: Temperament in human nature. New York: Basic Books.

Kagan, J. (1997). Temperament and the reactions to unfamiliarity. Child Development, 68, 139-143.

Kagan, J. (1998). Biology and the child. In W. Damon (Ed.), Handbook of child psychology: Vol. 3. Social, emotional, and personality development (pp. 117-235). New York: Wiley.

Kagan, J., Reznick, S., Clarke, C., Snidman, N., \& Garcia-Coll, C. (1984). Behavioral inhibition to the unfamiliar. Child Development, 55, 22122225.

Kagan, J., Reznick, S., \& Snidman, N. (1987). The physiology and psychology of behavioral inhibition in children. Child Development, 58, 14591473.

Kim, J., \& Cicchetti, D. (2010). Longitudinal pathways linking child maltreatment, emotion regulation, peer relations, and psychopathology. Journal of Child Psychology and Psychiatry and Allied Disciplines, 51, 706716.

Kochanska, G. (1991). Socialization and temperament in the development of guilt and conscience. Child Development, 62, 1379-1392.

Kochanska, G. (1993). Toward a synthesis of parental socialisation and child temperament in early development of conscience. Child Development, 64, 325-347.

Kochanska, G. (2001). Emotional development in children with different attachment histories: The first three years. Child Development, 72, 474490.

Kochanska, G., Barry, R. A., Aksan, N., \& Boldt, L. J. (2008). A developmental model of maternal and child contributions to disruptive conduct: The first six years. Journal of Child Psychology and Psychiatry and Allied Disciplines, 49, 1220-1227.

Kochanska, G., Barry, R. A., Jimenez, N. B., Hollatz, A. L., \& Woodard, J. (2009). Guilt and effortful control: Two mechanisms that prevent disruptive developmental trajectories. Journal of Personality and Social Psychology, 97, 322-333.

Kochanska, G., Coy, K. C., Tjebkes, T. L., \& Husarek, S. J. (1998). Individual differences in emotionality in infancy. Child Development, 69, 375390.

Kochanska, G., DeVet, K., Goldman, M., Murray, K., \& Putnam, S. P. (1994). Maternal reports of conscience development and temperament in young children. Child Development, 65, 852-868.

Kochanska, G., Gross, J. N., Lin, M. H., \& Nichols, K. E. (2002). Guilt in young children: Development, determinants, and relations with a broader system of standards. Child Development, 73, 461-482.

LeDoux, J. E. (1987). Emotion. In F. Plum (Ed.), Handbook of physiologyThe nervous system (Vol. 5, pp. 419-459). Washington, DC: American Physiological Society.
Lemery, K. S., Goldsmith, H. H., Klinnert, M. D., \& Mrazek, D. A. (1999) Developmental models of infant and childhood temperament. Develop mental Psychology, 35, 189-204.

Lewis, M., \& Ramsey, D. S. (1999). Effect of maternal soothing on infant stress response. Child Development, 70, 11-20.

Little, R. J. A., \& Rubin, D. B. (1987). Statistical analysis with missing data (2nd ed.). New York: Wiley Interscience.

Loeber, R., \& Stouthamer-Loeber, M. (1997). Development of juvenile aggression and violence. Some common misconceptions and controversies. American Psychologist, 53, 242-259.

Lovallo, W. R. (1997). Stress and health: Biological and psychological interactions. Los Angeles: Sage.

Lykken, D. T. (1995). The antisocial personalities. Hillsdale, NJ: Erlbaum.

Nigg, J. T. (2006). Temperament and developmental psychopathology. Journal of Child Psychology and Psychiatry, 47, 395-422.

O'Connor, L. E., Berry, J. W., Weiss, J., \& Gilbert, P. (2002). Guilt, fear, submission, and empathy in depression. Journal of Affective Disorders, 71, 19-27.

Pfeifer, M., Goldsmith, H. H., Davidson, R. J., \& Rickman, M. (2002). Continuity and change in inhibited and uninhibited children. Child Development, 73, 1474-1485.

Provost, M. A., \& Gouin-Decarie, T. (1979). Heart rate reactivity of 9- and 12-months old infants showing specific emotions in natural setting. International Journal of Behavioral Development, 2, 109-120.

PsyLab. (2007). PSYLAB program. Retrieved from http://www.psylab.com

Quay, H. C. (1965). Psychopathic personality as pathological stimulation seeking. American Journal of Psychiatry, 122, 180-183.

Raine, A. (1993). The psychopathology of crime: Criminal behavior as a clinical disorder. San Diego, CA: Academic Press.

Raine, A., Venables, P. H., \& Mednick, S. A. (1997). Low resting heart rate at age 3 years predisposes to aggression at age 11 years: Evidence from the Mauritius Child Health Project. Journal of the American Academy of Child \& Adolescent Psychiatry, 36, 1457-1464.

Rothbart, M. K. (1981). Measurement of temperament in infancy. Child Development, 52, 569-578.

Rothbart, M. K., Ahadi, S. A., \& Hershey, K. (1994). Temperament and social behavior in childhood. Merrill-Palmer Quarterly, 40, 21-39.

Scarpa, A., Raine, A., Venables, P. H., \& Mednick, S. A. (1997). Heart rate and skin conductance in behaviorally inhibited Mauritian children. Journal of Abnormal Psychology, 106, 182-190.

Schwartz, C. E., Snidman, N., \& Kagan, J. (1999). Adolescent social anxiety as an outcome of inhibited temperament in childhood. Journal of the American Academy of Child \& Adolescent Psychiatry, 38, 1008-1015.

Snoek, H., van Goozen, S. H. M., Matthys, W., Buitelaar, J. K., \& van Engeland, H. (2004). Stress responsivity in children with externalizing behavior disorders. Development and Psychopathology, 16, 389-406.

Strelau, J. (1998). Temperament: A psychological perspective. New York: Plenum Press.

Stuewig, J., Tangney, J. P., Heigel, C., Harty, L., \& McCloskey, L. (2010). Shaming, blaming, and maiming: Functional links among the moral emotions, externalization of blame, and aggression. Journal of Research in Personality, 44, 91-102.

Tangney, J. P., \& Dearing, R. (2002). Shame and guilt. New York: Guilford Press.

Tilghman-Osborne, C., Cole, D. A., \& Felton, J. W. (2010). Definition and measurement of guilt: Implications for clinical research and practice. Clinical Psychology Review, 30, 536-546.

Van Bokhoven, I., Matthys, W., van Goozen, S. H. M., \& van Engeland, H. (2005). Prediction of adolescent outcome in children with disruptive behavior disorders: A study of neurobiological, psychological and family factors. European Child and Adolescent Psychiatry, 14, 153-163.

van Goozen, S. H. M., Fairchild, G., Snoek, H., \& Harold, G. T. (2007). The evidence for a neurobiological model of childhood antisocial behavior. Psychological Bulletin, 133, 149-182.

van Goozen, S. H. M., Matthys, W., Cohen-Kettenis, P. T., Buitelaar, J. K., \& van Engeland, H. (2000). Hypothalamic-pituitary-adrenal axis and autonomic nervous system activity in disruptive children and matched controls. Journal of the American Academy of Child \& Adolescent Psychiatry, 39, 1438-1445.

Weiss, G., \& Hechtman, L. (1993). Hyperactive children grown up: ADHD in children, adolescents, and adults. New York: Guilford Press.

Zahn-Waxler, C., Kochanska, G., Krupnick, J., \& McKnew, D. (1990). Patterns of guilt in children of depressed and well mothers. Developmental Psychology 26, 51-59. 